\title{
Yelizaveta Bam
}

\section{Yelizaveta Bam}

\section{Esma Armağan Ertuğrul ${ }^{1}[$}

*Oyun çevrilirken Rusça aslından yararlanılmıştır. Metnin orijinali için bkz. Daniil Harms. Rasskazıy i povesti. Yelizaveta Bam, erişim 14 Nisan 2018 http://lib.ru/HARMS/harms.txt

'Yüksek Lisans Öğrencisi, İstanbul Üniversitesi, Sosyal Bilimler Enstitüsü, Tiyatro Eleştirmenliği ve Dramaturji Anabilim Dalı, İstanbul, Türkiye ORCID: E.E. 0000-0001-7260-045X

\section{Sorumlu yazar/Corresponding author:}

Esma Armağan Ertuğrul,

İstanbul Üniversitesi, Sosyal Bilimler Enstitüsü, Tiyatro Eleştirmenliği ve Dramaturji Anabilim Dalı, İstanbul, Türkiye

E-posta/E-mail: ertugrulesma@gmail.com

Başvuru/Submitted: 01.11.2019

Kabul/Accepted: 01.12 .2019

Atıf/Citation: Harms, Daniil. "Yelizaveta Bam", Çeviren Esma Armağan Ertuğrul. Tiyatro Eleştirmenliği ve Dramaturji Bölümü Dergisi 29, (2019): 129-169. https://doi.org/10.26650/jtcd.641386

\section{Yelizaveta Bam.}

Hemen şuna bak, kapı açılacak ve içeri girecekler... Beni yakalamak ve yeryüzünün suretinden kazımak için muhakkak girecekler. Ne mi yaptım? Ah bir bilebilseydim... Kaçmak mı? Ama nereye kaçmalı? Bu kapı merdivene çıkıyor. Merdivenlerde onlarla karşılaşırım. Pencereden mi? (Pencereden bakar.) Ohoo, çok yüksek! Atlayamam! Peki ne yapmalıyım? Ah! Ayak sesleri! Bunlar onlar! Kapıyı kilitleyeceğim ve açmayacağım. İstedikleri kadar çalsınlar.

(Kapı çalar. Ardından bir ses duyulur.)

\section{Bir Ses.}

Yelizaveta Bam, açın! Yelizaveta Bam, kapıyı açın! 


\section{Uzaktan bir ses.}

Ne yani, kapıyı açmıyor mu?

\section{Kapının hemen arkasından bir ses.}

Açın Yelizaveta Bam, açın.

\section{Kapının Arkasından Sesler}

\section{Birinci.}

Yelizaveta Bam, size derhal kapıyı açmanızı emrediyorum!

\section{İkinci.}

Şuna, açmazsa kapıyı kıracağımızı söyleyin. Bırakın da bir deneyeyim.

\section{Birinci.}

Eğer hemen açmazsanız, kapıyı kıracağız.

\section{İkinci.}

\section{Belki de burada değildir?}

\section{Birinci.}

(Sessizce.) Burada. Başka nerede olabilir? Merdivenlerden yukarı çıktı. Buradaysa tek bir kapı var. (Yüksek sesle.) Yelizaveta Bam, size son kez söylüyorum. Kapıyı açın. (Sessizlik.) Kapıyı kır.

\section{İkinci.}

Bıçağımız yok mu?

\section{Birinci.}

Hayır. Omzunla yap.

İkinci.

Bana mısın demiyor. Dur bakalım, bir de şöyle deneyeyim.

\section{Yelizaveta Bam.}

Bana ne yapmak istediğinizi söylemediğiniz müddetçe size kapıyı açmayacağım. 


\section{Birinci.}

Başınıza ne geleceğini gayet iyi biliyorsunuz.

\section{Yelizaveta Bam.}

Hayır, bilmiyorum. Beni öldürmek mi istiyorsunuz?

\section{Birinci.}

Büyük bir cezaya çarptırılacaksınız!

\section{İkinci.}

Her halükârda bizden kaçamayacaksınız!

\section{Yelizaveta Bam.}

Bana ne kabahat işlediğimi söylersiniz belki?

\section{Birinci.}

Zaten biliyorsunuz.

Yelizaveta Bam.

Hayır, bilmiyorum.

\section{Birinci.}

Müsaadenizle size inanmıyorum.

İkinci.

Suçlusunuz.

\section{Yelizaveta Bam.}

Ha ha ha ha! Beni öldürürseniz, vicdanınızın sizi rahat bırakacağını mı sanıyorsunuz?

\section{Birinci.}

Bunu, vicdanlarımızı da göz önünde bulundurarak yapacağız.

\section{Yelizaveta Bam.}

Bu durumda, ne yazık ki sizin vicdanınız yok. 


\section{İkinci.}

Nasıl olmaz? Pyotr Nikolayeviç, bu kadın bizim vicdanımızın olmadığını söylüyor.

\section{Yelizaveta Bam.}

Sizin de öyle İvan İvanoviç, sizde de vicdanın zerresi yok. Sahtekârın tekisiniz.

\section{İkinci.}

Kim sahtekâr? Ben mi? Ben mi? Ben mi sahtekârım?

\section{Birinci.}

Bekleyin İvan İvanoviç! Yelizaveta Bam, size emredi...

\section{İkinci.}

Hayır, biraz durun Pyotr Nikolayeviç, siz söyleyin, ben sahtekâr mıyım?

\section{Birinci.}

Kesin saçmalamayı!

\section{İkinci.}

Yani, size göre de ben bir sahtekârım, öyle mi?

\section{Birinci.}

Evet, sahtekârsınız!

\section{İkinci.}

Ah, demek size göre de ben bir sahtekârım. Böyle mi söylediniz?

\section{Birinci.}

Defolun gidin! Ne budala! Hala sorumlu olduğum bir iş var. Bir laf edildi, hala tatava yapıyorsunuz. Sonra, kimsiniz ki siz? Düpedüz aptal mısınız?

\section{İkinci.}

Siz de şarlatansınız!

\section{Birinci.}


Defolun!

\section{Yelizaveta Bam.}

İvan İvanoviç bir sahtekardır.

İkinci.

Bu yaptığınızı affetmeyeceğim!

\section{Birinci.}

Şimdi sizi merdivenlerden aşağı atarım!

(Yelizaveta Bam kapıyı açar.)

İvan İvanoviç.

Hele bir atmayı denesenize!

Pyotr Nikolayeviç.

Atarım, atarım, atarım, atarım!

Yelizaveta Bam.

Kolları kısa!

Pyotr Nikolayeviç.

Benim mi kollarım kısa?

Yelizaveta Bam.

E tabii!

İvan İvanoviç.

Sizin! Sizin! Söylesenize, onunkiler, değil mi?

Yelizaveta Bam.

Onunkiler!

Pyotr Nikolayeviç.

Yelizaveta Bam, böyle konuşmaya cüret edemezsiniz! 


\section{Yelizaveta Bam.}

Nedenmiş?

\section{Pyotr Nikolayeviç.}

Çünkü her tür sesten ${ }^{1}$ men edildiniz. İğrenç bir suç işlediniz. Bana küstahlık etmeye hakkınız yok. Suçlusunuz!

\section{Yelizaveta Bam.}

Neden?

\section{Pyotr Nikolayeviç.}

Ne neden?

\section{Yelizaveta Bam.}

Neden suçluyum?

\section{Pyotr Nikolayeviç.}

Çünkü her tür sesten men edildiniz.

\section{İvan İvanoviç.}

Her tür sesten men edildiniz.

\section{Yelizaveta Bam.}

Ama ben men edilmiş değilim ki. Saatinizi kontrol edebilirsiniz.

\section{Pyotr Nikolayeviç.}

İş oraya varmaz. Kapının önüne bir nöbetçi diktim. En ufak itiş kakışta İvan İvanoviç şu tarafa doğru hıçkıracak.

\section{Yelizaveta Bam.}

Gösterin. Lütfen gösterin.

Pyotr Nikolayeviç.

1 Burada "ses" anlamına gelen "golos” (голос) kelimesi, aynı zamanda “oy” anlamına gelmektedir. 
Pekâlâ, seyredin. Arkanızı dönmenizi rica ediyorum. Bir, iki, üç. (Komodini ${ }^{2}$ iter.)

\section{Yelizaveta Bam.}

Bir kez daha, lütfen! Bunu nasıl yapıyorsunuz?

\section{Pyotr Nikolayeviç.}

Çok basit. İvan İvanoviç, gösterin.

\section{İvan İvanoviç.}

Memnuniyetle.

\section{Yelizaveta Bam.}

Ama bu muhteşem bir şey! (Bağırır.) Anne! Buraya gel! Sihirbazlar geldi. Annem şimdi gelir... Tanışın, Piyotr Nikolayeviç, İvan İvanoviç. Bize bir şey gösterecek misiniz?

\section{İvan İvanoviç.}

Memnuniyetle.

\section{Pyotr Nikolayeviç.}

Hale op! Hemen, şimdi.

İvan İvanoviç.

Burada dayanacakbir yer yok.

\section{Yelizaveta Bam.}

Belki bir havlu istersiniz?

İvan İvanoviç.

Niye ki?

\section{Yelizaveta Bam.}

Öylesine. Hi-hi-hi-hi.

İvan İvanoviç.

2 Metinde itildiği belirtilen nesne "tumba" (тумба) olarak geçer. Bu kelime, "komodin"in dışında, "taş, bordür taş1, sütun, sütun tabanı, kürsü, kaide, duba” gibi anlamlara gelir. Oyunda Yelizaveta Bam kapıyı açtığı ve oyun kişilerinin içeri girebileceği düşünüldüğünden, kelime burada "komodin" anlamında kullanılmıştır. 
Olağanüstü derecede hoş görünüyorsunuz.

\section{Yelizaveta Bam.}

Öyle mi? Neden?

İvan Ívanoviç.

I-1-1-1-1... Çünkü bir “unutmabeni” çiçeğisiniz.

(Yüksek sesle hıçkırır.)

\section{Yelizavete Bam.}

Unutmabeni çiçeği miyim? Gerçekten mi? Siz de lalesiniz.

İvan İvanoviç.

Nasıl?

\section{Yelizaveta Bam.}

Lale.

\section{İvan İvanoviç.}

(Şaşkınlıkla.)

Çok hoş.

\section{Yelizaveta Bam.}

(Burnuna.)

Sizi koparmama izin verin.

\section{Baba.}

(Bas bir sesle.)

Yelizaveta, aptallaşma.

\section{Yelizaveta Bam.}

(Baba'ya.) Şimdi bırakacağım babacı̆̆ım. (İvan İvanoviç'e, burnuna.) Dört ayak üzerinde durun. 


\section{İvan İvanoviç.}

İzin verirseniz Yelizaveta Tarakanovna ${ }^{3}$, eve gitsem daha iyi olacak. Karım evde beni bekliyor. Karımın epeyce çocuğu var Yelizaveta Tarakanovna. Sizi sıktığım için bağışlayın. Beni unutmayın. Artık herkesin kapı dışarı ettiği biriyim. Niye, diye mi soruluyor? Yoksa bir şey mi çaldım? Neyse ki hayır! Yelizaveta Eduardovna, ben dürüst bir insanım. Evde karım var. Karımın bir sürü çocuğu var. Çocuklar iyi. Her biri dişlerinde, bir kibrit kutusu tutar. Artık beni bağışlayın. Ben Yelizaveta Mihaylovna, eve gidiyorum.

(Anne, müzik eşliğinde şarkı söyler.)

\section{Anne. $^{4}$}

İşte alev aldı sabah, kızıla boyanıyor sular, uçuyor gölün üzerinde çevik bir martı ve $\mathrm{vb} \ldots$

$v b$.

\section{Pyotr Nikolayeviç.}

İște geldik!

Baba.

Şükürler olsun Tanrım!

(Çıkarlar.)

Yelizaveta Bam.

Anne, sen gezmeye gelmiyor musun?

Anne.

Gelmemi istiyor musun?

Yelizaveta Bam.

Hem de nasıl.

Anne.

3 “Tarakan” (таракан) Rus dilinde "hamamböceği” anlamına gelir. Dolayısıyla burada kullanılan şekliyle Tarakanovna, "Hamamböceğiovna" şeklinde de ifade edilebilir ve "Yelizaveta Tarakanovna" ismi, "Hamamböceğinin k1zı Yelizaveta" anlamındadır.

4 Rus dilinde "anne" kelimesi "mat" (мать) veya "mama" (мама) ile ifade edilirken burada kullanılan biçim olan "mamaşa" (мамаша) daha çok konuşma dilinde kullanılır ve daha aşağılayıcı bir anlam taşır. 
Hayır, gelmiyorum.

\section{Yelizaveta Bam.}

Gidelim o z-z-a-aman!

\section{Anne.}

Gidelim haydi, gidelim.

(Çıkarlar.)

(Sahne boştur.)

İvan İvanoviç ve Pyotr Nikolayeviç.

(Koşarak girerek.)

Nerede, nerede, nerede

Yelizaveta Bam,

Yelizaveta Bam,

Yelizaveta Bam?

\section{Pyotr Nikolayeviç.}

Burada burada burada.

İvan İvanoviç.

Orada orada orada.

Pyotr Nikolayeviç.

Nereye geldik İvan İvanoviç?

İvan İvanoviç.

Kilitli kaldık sizinle Pyotr Nikolayeviç.

Pyotr Nikolayeviç.

Ne rezillik ama! Beni itmemenizi rica ediyorum!

İvan İvanoviç. 
Alın size bir sterlin. ${ }^{5} \mathrm{Ne}$ beş eksik ne beş fazla.

\section{Pyotr Nikolayeviç.}

Yelizaveta Bam nerede?

İvan İvanoviç.

Niye lazım size?

\section{Pyotr Nikolayeviç.}

Öldürmek için!

İvan İvanoviç.

Hımm, Yelizaveta Bam orada, bankta oturuyor.

\section{Pyotr Nikolayeviç.}

Öyleyse var gücümüzle koşalım.

(İkisi de oldukları yerde koşarlar. Pyotr Nikolayeviç ile İvan İvanoviç koştukları sırada sahnenin önüne bir kütük getirilir ve kütük testereyle kesilir.)

Rap rap,

Ayaklarla

Batiyor

Dağların ardında

Pembe bulutlarla

Puh puh,

Lokomotifle,

Huk huk,

Kesilmiş

Puhu baykuşun dalı!

5 Burada sterlin anlamında kullanılan "funt” (фунт) kelimesinin bir diğer anlamı, eski bir Rus ölçü birimi olan "libre”dir. Libre kullanıldığında cümlenin anlamı eksik kaldığı için libre yerine sterlin kullanılmıştır. 
(Yelizaveta Bam dekora ${ }^{6}$ doğru geçer ve dekorun arkasına oturur.)

\section{Yelizaveta Bam.}

Beni mi arıorsunuz?

Pyotr Nikolayeviç.

Sizi arıyoruz! Vanka, o burada!

İvan İvanoviç.

Nerede, nerede, nerede?

Pyotr Nikolayeviç.

Burada, farluşkanın ${ }^{7}$ altında.

(Sahneye bir Dilenci çıkar.)

İvan İvanoviç.

$\mathrm{Onu}^{8}$ dışarı çıkar!

Pyotr Nikolayeviç.

Yetişilmiyor!

Dilenci.

(Yelizaveta Bam'a.)

Yoldaş $^{9}$, yardım edin.

İvan İvanoviç.

(Kekeleyerek.)

Gelecek sefer daha tecrübeli olacağım. Herkes gibi fark ettim.

6 Burada kullanılan kelime "kulisa" (кулиса) "sahnenin kenarlarına yerleştirilen dekorun yan taraftaki düz parçası" anlamına gelir. "Oyuncuların hazırlandıkları yer" ya da "perde arkası" anlamındaki kulis ise daha çok kelimenin çoğul haliyle kullanılır. Bkz. Kulica, erişim 16 Nisan 2018, https://dic.academic.ru/dic.nsf/ushakov/846030.

7 İ. Bahterev, "farluşka” (фарлушка) kelimesinin, özel bir kullanım amacı olmayan bir nesneyi belirtmek için uydurulduğunu hatırlatıyor. Bkz. Daniil Harms, Tsirk Şardam, Der. Valeriy Nikolayeviç Sajin (Sankt-Peterburg: Kristall, 2001), 930.

8 Kastedilen Yelizaveta Bam'dır.

9 Burada “yoldaş" anlamında kullanılan kelimenin bir diğer anlamı "arkadaş”tır. 


\section{Yelizaveta Bam.}

$$
\text { (Dilenci'ye.) }
$$

Hiçbir şeyim yok.

\section{Dilenci.}

Hiç değilse üç beş kuruş.

\section{Yelizaveta Bam.}

Şu amcaya sor.

(Pyotr Nikolayeviç’i gösterir.)

\section{Pyotr Nikolayeviç.}

(İvan Ívanoviç'e, kekeleyerek.)

Şu yaptığına bak!

İvan İvonoviç.

(Kekeleyerek.)

Kökünü kazıyorum.

\section{Dilenci.}

Yardım edin yoldaşlar.

\section{Pyotr Nikolayeviç.}

(Dilenci'ye.)

Haydi. Tırman şuraya.

\section{İvan İvanoviç.}

Ellerinle şu taşa dayan.

(Dilenci, dekora ${ }^{10}$ çıkar.)

\section{Pyotr Nikolayeviç.}

10 Burada kullanılan kelime "kulisa" (кулиса) "sahnenin kenarlarına yerleştirilen dekorun yan taraftaki düz parçası" anlamına gelir. Bkz. Dipnot 7. 
Sorun yok, hallediyor.

Yelizaveta Bam.

Otursanıza siz de. Ne bakıyorsunuz?

İvan İvanoviç.

Teşekkür ederim.

Pyotr Nikolayeviç.

Oturalım.

(Otururlar.)

Yelizaveta Bam.

Niyeyse kocam gelmiyor. Nereye kayboldu?

Pyotr Nikolayeviç.

Gelecek. (Fırlar ve sahnede koşuşturur.) Kış kış! ${ }^{11}$

İvan İvanoviç.

Ha-ha-ha. (Pyotr Nikolayeviç'in arkasından koşar.) Ev nerede ki?

\section{Yelizaveta Bam.}

Burada işte, bu yolun ötesinde.

(Sahneye, elinde kuş tüyünden bir kalemle Baba ${ }^{12}$ girer.)

\section{Pyotr Nikolayeviç.}

(İvan İvanoviç'e vurur.) Seni beş para ${ }^{13}$ etmez adam!

\section{Yelizaveta Bam.}

İvan İvanoviç, buraya koşun!

11 Metinde kullanıldığı şekliyle “çur çura!" (чyp-чypa), bir şeye dokunmanın, herhangi bir sınırı geçmenin, bir gayeyi aşmanın "yasak” olduğunu belirtmeye yarayan nidadır. Özellikle çocukların oyunlarında kullandıkları kelime, birtakım "karanlık güçlere” karşı söylenen "büyü sözü”dür.

12 Rus dilinde "baba", "otets" (отец) уа da "рара" (папа) ile ifade edilirken burada kullanılan biçim olan "papaşa" (папаша) daha çok konuşma dilinde kullanılır ve daha aşağılayıcı bir anlam taşır.

13 Söz öbeğinin orijinali “on beş kuruşluk”tur; ancak söylenmek istenen düşünüldüğünde böylesi daha uygun bulunduğundan bu şekilde çevrilmiştir. 


\title{
İvan İvanoviç.
}

Ha-ha-ha, ayaklarım yok ki!

\section{Pyotr Nikolayeviç.}

E sen de dört ayak üzerinde koş!

\section{Baba.}

Hakkında yazılmış olan.

\section{Yelizaveta Bam.}

Kim beş para etmez?

\section{İvan İvanoviç.}

Ben, ha-ha-ha, pantolonluyken!

\section{Pyotr Nikolayeviç ve Yelizaveta Bam.}

Ha-ha-ha-ha!

\section{Baba.}

Kopernik en büyük bilim adamıydı. ${ }^{14}$

\section{İvan İvanoviç.}

(Yere yapışır.)

Kafamda saç var.

\section{Pyotr Nikolayeviç ve Yelizaveta Bam.}

\author{
Ha-ha-ha-ha-ha-ha-ha!
}

İvan İvanoviç.

Yerde boylu boyunca yatıyorum!

(Anne, sahneye girer.)

14 Metnin orijinalinde bu cümle "Kopernik bıyl velişayşim uçyonıym” (Коперник был велишайшим ученым) olarak geçer. "Velişayşiy” (велишайший) kelimesi, (bilinçli ya da bilinçsiz olarak) yanlış yazıldığı düşünülerek “en büyük” anlamına gelen "veliçayşiy” (величайший) düşünülerek çevrilmiştir. 


\section{Pyotr Nikolayeviç ve Yelizaveta Bam.}

Ha-ha-ha-ha-ha!

\section{Yelizaveta Bam.}

Ay ay, yapamam!

\section{Baba.}

Kuş satın alırken bak; dişleri var mı yok mu diye. Dişleri varsa, kuş değil demektir. (Çıkar.)

\section{Pyotr Nikolayeviç.}

(Elini kaldırarak.) Sözlerime iyice kulak vermenizi rica ediyorum. Size, her talihsizliğin ansızın meydana geldiğini kanıtlamak istiyorum. Henüz tümüyle genç bir adamken, kapısı gıcırdayan bir kulübede yaşardım. Bu kulübede tek başıma yaşardım. Benim dışımda bir tek fareler ve hamamböcekleri vardı. Her tarafta hamamböcekleri olurdu, gece çöktügüünde kapıyı kapatıp ışı̆̆ı söndürürdüm. Hiçbir şeyden korkmadan uyurdum.

\section{Sahnenin Arkasından Bir Ses.}

$$
\text { H i ç b i ş e y d e n! }
$$

Anne.

Hiçbir şeyden!

\section{Sahnenin Arkasından Flüt Sesi.}

$$
!-!
$$

İvan İvanoviç.

Hiçbir şeyden!

\section{Kuyruklu Piyano.}

$!-!$

\section{Pyotr Nikolayeviç.}

Hiçbir şeyden. (Sessizlik.) Korkacak hiçbir şeyim yoktu. Sahiden. Soyguncular gelebilir ve evin altını üstüne getirebilirlerdi. Ne bulurlardı? Hiçbir şey. 


\section{Sahnenin Arkasından Bir Düdük.}

$$
!-!
$$

(Sessizlik.)

\section{Pyotr Nikolayeviç.}

Kim yanıma sokulabilirdi ki gece vakti? Başka kimse yoksa madem? Değil mi ama?

\section{Sahnenin Arkasından Bir Ses.}

Kimse yok mu başka?

\section{Pyotr Nikolayeviç.}

Öyle değil mi ya? Ama bir gün uyanıyorum...

\section{İvan İvanoviç.}

...Ve kapının açık olduğunu görüyorum. Kadının biri dikiliyor kapıda. Doğrudan yüzüne bakıyorum. Duruyor. Ortalık yeterince aydınlıktı. Sabaha karşı olmalıydı. Her halükârda iyice gördüm yüzünü. O, buydu işte. (Yelizaveta Bam’ı gösterir.) Benziyordu o vakit...

\section{Herkes.}

Bana!

\section{İvan İvanoviç.}

Ben de onu diyorum. ${ }^{15}$

\section{Yelizaveta Bam.}

Ne diyorsunuz?

\section{İvan İvanoviç.}

Onu diyorum işte. Sonra artık çok geç olduğunu düşünüyorum. Beni dinliyor. (Yelizaveta Bam ve Ivvan İvanoviç dışında herkes çıkar.) Bunu neyle yaptığını sordum ona.

15 Bu cümlenin aslı “Говорю, чтобы быть.” tır. (Govoryu, chtobıy bıyt.) Ancak gerek Rus dilinde çok rastlanan bir kalıp olmadığından gerekse oyunda bilinçli bir şekilde yaratılan anlamsal kopukluktan dolayı bu cümlenin anlamı tam olarak anlaşılmamaktadır. Buna karşın cümle, diğer cümlelerle kendi içinde tutarlı bir bütünlük sağlayacak şekilde bir ara söz gibi kullanıldığından bu şekilde çevrilmesi uygun bulunmuştur. 
Espadronla ${ }^{16}$ dövüştüklerini söylüyor. Dürüstçe dövüştüler ama öldürmesi onun suçu değil. Sahi, Pyotr Nikolayeviç'i neden öldürdün?

\section{Yelizaveta Bam.}

Hayda, ben kimseyi öldürmedim!

İvan İvanoviç.

Birini yakalayıp kılıçtan geçirmek! Ne kalleşlik ama! Hurra! Sen yaptın, niye ama!

Yelizaveta Bam.

(Diğer tarafa doğru yürür, oradan.)

Unuuuuuuu-u-u-u-u-u!

İvan İvanoviç.

Kurt.

\section{Yelizaveta Bam.}

Unuuuuuuu-u-u-u-u-u!

İvan İvanoviç.

Ku-u-u-u-urt.

\section{Yelizaveta Bam.}

(Titrer.)

U-u-u-u-u- kara erikler.

İvan İvanoviç.

Bü-bü-bü-bü-büyük anne.

Yelizaveta Bam.

Neşe!

İvan İvanoviç.

Sonsuza dek mahvedildi.

16 Eskrim eğitiminde kullanılan bir tür kılıç. 


\section{Yelizaveta Bam.}

Yağız bir at, üstündeyse atın bir asker!

\section{İvan İvanoviç.}

(Bir kibrit yakar.)

Küçük bir güvercindir Yelizaveta!

\section{Yelizaveta Bam.}

Omuzlarım, doğan güneş gibi.

(Sandalyeye çıkar.)

\section{İvan İvanoviç.}

(Çömelir.)

Benim ayaklarımsa, hıyar gibi!

\section{Yelizaveta Bam.}

(Daha yükseğe çıkarak.)

Hayda! Bir şey demedim ki!

İvan İvanoviç.

(Yere uzanarak.)

Hayır hayır, bir şey yok, bir şey yok. G.g. pş. pş.

\section{Yelizaveta Bam.}

(Ellerini kaldırarak.)

Ku-ni-ma-ga-ni-li-va-ni-bauuu!

İvan İvanoviç.

(Yere uzanmış, şarkı söyler.)

Kedicik Murka

Sayıklardı süt diye 
Atlard1 yastığın

Ve sobanın üstüne.

Hop hop,

Zıp zıp.

Yelizaveta Bam.

(Băğtrır.)

Dzıy ${ }^{17}$ kapısı! Gömlek! Urgan!

İvan İvanoviç.

(Doğrularak.)

İki marangoz geldiler koşarak ve soruyorlar: Ne var?

Yelizaveta Bam.

Köfteler! Varvara Semyonna! ${ }^{18}$

İvan İvanoviç.

(Bă̆ırır. Dişlerini sıkarak.)

Üzerinde bir ip cambazı teli-li-li-li ${ }^{19}$ !

Yelizaveta Bam.

(Sandalyeden atlar.)

Pırıl pırılım!

İvan İvanoviç.

17 Metnin bu ifade "Dzıy kalitka” (Дзы калитка) şeklinde kullanılıyor. Herhangi bir anlam ifade etmeyen “Дзы” (dzıy) kelimesi, akla fütüristlerin "akıl ötesi” dilini getiriyor. Bununla birlikte "dzıy” kelimesi bazı kaynaklarda Çin dilinde özel ada teşekkül eden "Tzu” olarak çevrilmiş; fakat ifadenin bu anlamda kullanılıp kullanılmadığı belli olmadığından kelime "dzıy" șeklinde bırakıldı.

18 "Varvara Semyonna" (Варвара Семенна) ismindeki "Varvara” bir yandan eril "varvar" kelimesinin dişil şekli "varvara" olarak "barbar" anlamını taşırken diğer yandan kadın ismi "Varvara" anlamına gelebilecek şekilde kullanılmıştır.

19 Metinde bu cümle şu şekilde yer alır: "Plyacunya na provolo-o-o!” (Плясунья на проволо-о-о!”). "Provolo-o-о" kelimesi, buradaki şekliyle eksik bir kelimedir. Bu sebeple bu kelime, sessel özellikleri bakımından kelimeye ve cümlenin anlamına en yakın sözcük olan "tel” anlamındaki “provolok” (проволок) kelimesinin tamamlanmamış hali olarak kullanılmıștır. 


\section{(Odanın derinliklerine doğru koşar.)}

Bu odanın hacmi tarafimızca bilinmiyor.

(Dekorlar Anne ve Baba'nın üzerine düşer.)

\section{Yelizaveta Bam.}

(Sahnenin diğer köşesine koşar.)

Sayalım halkım! ${ }^{20}$

İvan İvanoviç.

(Sandalyeye atlayarak.)

Pensilvanyalı bir çobanın saadeti ve çoba-ba-ba-ba!

\section{Yelizaveta Bam.}

(Başka bir sandalyeye atlayarak.)

İvan İva-va-va-va!

Baba.

(Kozală̆l göstererek.)

Bir kozalak ağa-a-a-açt!

İvan İvanoviç.

(Sandalyeden.)

Şimdilik-k-k!

Baba.

Al ba-ba-ba! ${ }^{21}$

Anne.

20 Metnin orijinalinde bu cümle “Svoyi lyudi soçtemsya!” (Свои люди, сочтемся!) şeklindedir. A. N. Ostrovskiy’nin aynı isimde bir oyunu vardır. Bu oyun Türkçe’ye “Bu Bir Aile Sorunudur ve Aile İçinde Halledilecek” şeklinde çevrilmiştir.

21 Metinde "Возьми посмо-о-о!" (vozmi posmo-o-o) şeklinde olan ifadesindeki "посмо-о-о" (posmo-о-о) kelimesi, daha önceki cümlelerde olduğu gibi eksik olduğu varsayılarak "bak” anlamına gelen “посмотри” kelimesinin tamamlanmamış hali şeklinde değiştirilmiştir. 
Au-u-u-u-u!

\section{Yelizaveta Bam.}

Altında buldum huş ağaçlarının-nın-nın! $!^{22}$

İvan İvanoviç.

Haydi göle gidelim!

Baba.

Au-u-u-u-u!

Yelizaveta Bam.

Au-u-u-u-u!

İvan İvanoviç.

Dün Kolka’ya rastladım.

Anne.

Daha nele-le-le-ler?

İvan İvanoviç.

Evet ya. Rastladım rastladım. Bir bakıyorum Kolka geçiyor, elinde bir elma taşıyor. "Ne?" diyorum, "Satın aldın?". "Evet." diyor, "Satın aldım.” Aldı ve uzaklaştı sonra.

\section{Baba.}

Söyleyin lütfe-fe-fe-fe-fen!

\section{İvan İvanoviç.}

Evet. Sordum ona: "Elmaları satın mı aldın; çaldın mı yoksa?" "Niye çalayım? Satın aldım." diyor oysa. Ve gitti daha uzağa.

\section{Anne.}

Nereye gitti peki?

22 Cümlenin orijinali “Нашла подберезови-и-и” (naşla podberyozovi-i-i) şeklindedir. Cümledeki “подберезови-и-и” kelimesi, "altında" anlamına gelen “под” edatıyla "huş ağacı" anlamına gelen “берёза” (beryoza) kelimesinden türetilen "берёзовые” (beryozovıye: huşgiller) kelimelerinin birleşiminden oluşur. 


\section{İvan İvanoviç.}

Bilmiyorum. Çalmadı, satın almadı. Çekti gitti.

\section{Baba.}

Çok da nazik olmayan bu selamla kız kardeşi onu, bir yığın altın masa ve koltuğun kurulu olduğu daha açık bir yere götürdü ve on beş tane genç kız tanrı ne verdiyse oturarak kendi aralarında neşeyle gevezelik ediyorlardı. Tüm bu kızlar, sıcak bir ütüye şiddetle muhtaçtılar ve hepsi, garip bir tavırla gözlerini dört döndürerek kendilerini belli ediyor ve bir an bile durmadan konuşuyorlard.

İvan İvanoviç.

Arkadaşlar, hepimiz burada toplandık. Oley!

\section{Yelizaveta Bam.}

Oley!

Anne ve Baba.

Oley!

\section{İvan İvanoviç.}

\section{(Titrer ve bir kibrit tutuşturarak.)}

Size, doğduğum andan beri otuz sekiz yıl geçtiğini söylemek isterim.

Baba ve Anne.

Oley!

\section{İvan İvanoviç.}

Yoldaşlar. Benim bir evim var. Evde karım oturuyor. Karımın epeyce çocuğu var. Saydım, on taneler.

\section{Anne.}

(Yeri çiğneyerek.)

Darya, Marya, Fyodor, Pelageya, Nina, Aleksandr ve dört tane daha.

Baba. 
Hepsi oğlan mı?

\section{Yelizaveta Bam.}

(Sahnenin etrafinda koşuşturur.)

Kaçtım dört bir yandan!

Kaçtım ve başladım koşmaya!

Kaçtım ve al koşmak sana!

Anne.

(Yelizaveta'nın arkasından koşar.)

Ekmek var mı? Yer misin? ${ }^{23}$

\section{Yelizaveta Bam.}

Çorba var mı? Yer misin?

Baba.

Et var mi? Yer misin?

(Koşar.)

Anne.

Un var mı? Yer misin?

İvan İvanoviç.

Şalgam var mı? Yer misin?

(Koşar.)

\section{Yelizaveta Bam.}

Koyun eti var mi? Yer misin?

\section{Baba.}

23 Rusçadaki “yest” (есть) fiili, hem "mevcut olmak” hem de "(bir şey) yemek” anlamına gelmektedir. Bu fiilin anlamı, zamir çekimine göre anlaşılır. Metinde “есть” (yest) fiili her iki anlamı da kast edilerek “есшь” (уеsş) şeklinde kullanılmıştır. Bu sebeple aynı fiil sayfa boyunca bu şekilde kullanılmıştır. 
Köfte var mı? Yer misin?

Anne.

Ah, ayaklarım yoruldu!

İvan Ívanoviç.

Ah, ellerim yoruldu!

\section{Yelizaveta Bam.}

Ah, makas yoruldu!

Baba.

Ah, yaylar yoruldu!

Anne.

Kapı balkona açılıyor!

İvan İvanoviç.

Dördüncü kattan atlamak isterdim.

Yelizaveta Bam.

Kaçtım ve başladım koşmaya! Kaçtım ve al koşmak sana!

Baba.

Nöbetçi, sağ elim ve burnum, tıpkı sol elim ve kulağım gibidirler!

Koro.

(Uvertür havasında müzik eşliğinde.)

Görüşmek üzere! Görüşmek üzere!

$$
! !-!
$$

Yukarıda konuşuyor bir çam,

Karanlık, diyor, etrafsa.

Üzerinde, diyor çamın, bir yatak, 
Uzaniyor kocamsa yatakta.

Görüşmek üzere! Görüşmek üzere!

Bir keresinde koşup gelmiştik biz,

!-!

Bir eve uçsuz bucaksız.

Penceredense yukarı bakıyor

Gözlükleri arasından genç bir ihtiyar.

Görüşmek üzere! Görüşmek üzere!

!!-!

!!-!

Açılıyor yakalar, ${ }^{24}$

Görünüyorlar! - !

(Uvertür.)

İvan İvanoviç.

Sen kırıksın.

Sandalyen kırık.

Keman.

Pa pa pi pa

Pa pa pi pa.

Pyotr Nikolayeviç.

24 Metinde bu cümle "Rastvorilis vorota" (Растворились ворота) şeklinde geçer. Normalde "büyük kapı" anlamına gelen "vorota" (ворота) kelimesi yerine burada "уaka" anlamına gelen "vorot” (ворот) kelimesinin çoğulu olan "vorota” (ворота) kullanılmıştır; zira metinde "açılmak" anlamına gelen fiil, "rastvorilis" (растворились) şeklinde, çoğul halde kullanılmıştır. 


\section{Kalk Berlin olarak}

\section{Giy pelerinini.}

\section{Keman.}

Pa pa pi pa

Pa pa pi pa.

\section{Pyotr Nikolayeviç.}

Sekiz dakika

Geçiyor farkına bile varmadan.

Keman.

Pa pa pi pa pa

Pa pa pi.

\section{Pyotr Nikolayeviç.}

Size kesildi fatura,

Uyandırın çetin ${ }^{25}$

Müfrezeyi veya bölüğü

Bir makineli sürüklemek adına.

\section{Davul.}

$$
\begin{gathered}
\text { !--! } \\
\text { !--!- } \\
\text { !--!-!-! }
\end{gathered}
$$

\section{Pyotr Nikolayeviç.}

\section{Parçacıklar uçuşurdu haftadan haftaya.}

25 Metinde bu cümle "budite trudınnу” (будите трудыны) şeklinde geçer. "Trudıynıy” (трудыны) kelimesine gelen son ek, bilinçli ya da bilinçsiz olarak kelimenin anlamını bozar. Bu sebeple kelime, kökü "trud” (труд: iş, emek) dikkate alınıp kelimeye son ek "nıy” (ный) getirildiği düşünülerek "zor, sıkı, güç” anlamına gelen "trudnıy” (трудный) anlamında kullanılmıştır. 


\section{Siren ve Davul.}

Via-a bum, bum via-a-a bum.

\section{Pyotr Nikolayeviç.}

Sikuraya $^{26}$ gelin fark etmedi, birinci kaptanın gürültüsünü.

\section{Siren.}

Via via via via.

\section{Pyotr Nikolayeviç.}

Yardım edin şimdi, yardım edin, salata ve su lazım bana.

Keman.

Pa pa pi pa.

Pa pa pi pa.

İvan İvanoviç.

Anlatsanıza Pyotr Nikolayeviç, şu dağdaydınız.

\section{Pyotr Nikolayeviç.}

Daha yeni geldim oradan, epey güzel bir yer.

Çiçekler büyüyor. Hışırdıyor ağaçlar.

Bir baraka dikiliyor, ağaçtan bir kulübe,

Bir alev parlıyor barakanın içinde,

Aleve üşüşüyor dutlar,

Gececi sivrisinekler pencereyi tıklatıyorlar.

Bazen konup pır diye uçuveriyor altında

Çatının; yaşlı, eşkıya bir çobanaldatan.

26 Hiçbir anlam ifade etmeyen "sikuraya" (сикурая) kelimesi akla yine fütüristlerin "akıl ötesi” dilini getiriyor. Kelimenin buradaki kullanımı, Rus dilinde sıfat fiil yapmak için kullanılan "-aya" (-ая) son ekini hatırlatsa da anlamlı herhangi bir referans bulunamadığından kelime olduğu gibi bırakılmıştır. 
Köpeğin zincirini kımıldatıyor hava,

Ve havlıyor köpekçik önündeki boşluğa,

Ona cevaben görünmez yusufçuklar,

Bir büyü mırıldanıyorlar uyumla.

\section{İvan İvanoviç.}

Peki, ağaçtan olan, baraka denen, içinde bir alevin parıldayıp kıpırdandığı bu kulübede kim yaşıyor?

\section{Pyotr Nikolayeviç.}

Kimse yaşamıyor

Ve kapısı açılmıyor.

Yalnızca fareler avuçlarıyla un ovuyorlar içinde

İçinde yalnız lamba ışıldıyor biberiyeyle.

Ve bütün gün oturuyor bir münzevi gibi

Fırının ${ }^{27}$ üzerinde hamamböceği.

İvan İvanoviç.

Peki lambayı kim yakıyor?

\section{Pyotr Nikolayeviç.}

Kimse. Kendi kendi yanıyor.

İvan İvanoviç.

Ama böyle şey olmaz ki!

\section{Pyotr Nikolayeviç.}

Boş bu sözler, aptalca!

Sonsuz bir devinim söz konusu,

27 Burada "fırın" olarak kullanılan kelime "peçka" (печка), hem firın hem soba olarak kullanılabilen, üzerinde yatılabilecek büyüklükte olan bir çeşit Rus ısıtma sistemidir. 
Hafif elementlerin soluğu,

Gezegenlere ait bir koşu, dünyanın dönüşü,

Akıl almaz değişimi gece ve gündüzün.

Issız doğanın ahengi,

Vahşi hayvanların öfkesi ve gücü,

Ve insanoğlunca fethi,

Işık ve dalga yasalarının.

İvan İvanoviç.

(Bir kibrit yakarak.)

Şimdi anladım,

Anladım, anladım.

Teşekkür ediyor ve önünde eğiliyorum

Ve her zamanki gibi merak ediyorum:

Saat kaç? Söyleyin bana.

\section{Pyotr Nikolayeviç.}

Dört. Ohoo, öğle yemeği vakti!

İvan İvanoviç gidelim

Ama aklından çıkarma sakın, yarın gece

Öleceğini Yelizaveta Bam’ın.

Baba.

(Girerek.)

Yelizaveta Bam,

Kızımdır benim,

İstediğiniz ertesi gece 
Öldürmeyi ve asmayı çam ağacının birine,

$$
\text { Zariftir, }
$$

Bilsin diye çevredeki tüm hayvanlar

Ve bütün ülke.

İşte emrediyorum size,

El birliğiyle unutmanızı Yelizaveta Bam'1,

Yasaların aksine.

\section{Pyotr Nikolayeviç.}

Hele bir mâni olmayı dene,

Anında ayaklarımın altına alırım seni,

Sonra da kızıl kırbacımla

Kırarım eklemlerini.

Parça pinçik eder, savurup sürükleyerek

Rüzgâra salarım horoz gibi.

\section{İvan İvanoviç.}

Onu herkes tanır,

Kendisi benim efendim ve arkadaşımdır,

Tek kanat çırpışıyla

Denizleri yerinden oynatır,

Baltayı tek bir vuruşuyla

Keser koca bir ormanı ve devirir dağları,

Tek bir soluğuyla

Hissedilir dört bir yanda varlığı.

Baba. 
Haydi dövüşelim büyücü,

Sen sözünü kullan, bense elimi,

Geçecek bir dakika, bir saat geçecek,

Ardından geçecek bir saat daha.

Öleceksin sen, öleceğim ben,

Susacak her şey orada,

Yeter ki bayram etsin kızım,

Yelizaveta Bam.

\section{İKİ KAHRAMANIN DÖVÜŞÜ}

\section{İvan İvanoviç.}

İki kahramanın dövüşü!

Metin: İmmanuil Krasdayteyrik.

Müzik: Hollandalı çoban Veliopag'ın.

Hareket: Meçhul bir gezgine ait.

Çan başlangıcı gösterir!

\section{Salonun farklı uçlarından sesler.}

İki kahramanın dövüşü!

Metin: İmmanuil Krasdayteyrik.

Müzik: Hollandalı çoban Veliopag'ın.

Hareket: Meçhul bir gezgine ait.

Çan başlangıcı gösterir.

İki kahramanın dövüşü! 
Çan.

Bum, bum, bum, bum, bum.

\section{Pyotr Nikolayeviç.}

Kurıbbiyr daramur

Diyndiri

Slakatıyr pakaradagu

Dıy kıy çiri kiri kiri

Zanudila habakula

He-e-el

Hançu ana kudıy

Stum çi na lakudıy

Para viy na liytena

He-e-el

Çapu açapali

Çapatali mar

Nabaloçina

He-e-el

(Elini kaldırır.)

Baba.

Bırak uçsun güneşe

Kanatlı papağan

Bırak sönük kalsın altın gibi

Uzun bir gün, bırak.

Bırak yarıp geçsin ormanı 
Toynağın sesi ve gürültüsü

Ve çığlık çığglı̆ga firlayacak tekerlekten

Sandığın özü.

Ve şövalye oturarak masaya

Ve dokunarak kılıca, kaldıracak kâseyi ve sonra

Üzerinden kâsenin haykıracak:

Bu kâseyi armağan ediyorum

Hararetli dudaklarıma.

İçlerinden en iyisi için,

İçiyorum Yelizaveta Bam için.

Onun ki beyaz ve körpecik elleri,

Okşadılar ceketimi...

Yaşa Yelizaveta Bam,

Yüz bin yıl yaşa.

\section{Pyotr Nikolayeviç.}

Pekâlâ, başliyoruz.

Dikkatle takip etmenizi rica ediyorum,

Kılıçlarımızın salınımlarını

Savrulduğu yeri ucunun,

Ve karşılık verdiği yönü.

İvan İvanoviç.

Demek soldan gelen hamleleri sayıyorum.

Baba.

Yanını kesiyorum, kesiyorum sağını, 
Baksın herkes başının çaresine!

Etrafta uğulduyor artık bir meşe ormanı,

Büyüyorlar bahçenin çevresinde.

\section{Pyotr Nikolayeviç.}

Etrafina daha az bak,

Gözlemle hareketini daha çokça,

Demir merkezlerin ve yoğunlaşmasını ölümcül güçlerin.

\section{Baba.}

Demire övgü, karborunduma! ${ }^{28}$

O tutturur kaldırımları birbirine

Ve 1şıldayarak elektrikle

Hırpalar düşmanı ölünceye kadar!

Demire övgü! Savaşa şarkı!

O endişelendirir haydudu,

Bebeği dönüştürür gence,

Hırpalar düşmanı ölünceye kadar!

Savaşa şark1! Şan kuştüylerine!

Onlar ki uçuşurlar havada

Acımasızca gözlerini doldurup

Paralarlar düşmanı ölünceye kadar!

Şan kuştüylerine! Bilgelik taşa.

O ki gölgesinde uzanır çamın ciddiyetle,

Altından akıp gider su,

28 Karborundum: Aşındırıcı madde olarak kullanılan silisyum karbürün ticaretteki adı. 
Ölmüş düşmana doğru.

(Pyotr Nikolayeviç düşer.)

\section{Pyotr Nikolayeviç.}

Yaralı halde düştüm yere,

Elveda Yelizaveta Bam,

Git dağdaki kulübeme,

Ve kal orada.

Koşuşturacaklar senin

Ve ellerinin üzerinde sağır fareler, sonrasındaysa

Münzevi bir hamamböceği.

(Çan çalar.)

Duyuyorsun, çınlıyor çan,

Çatının üzerinde bim ve bam.

Bağışla beni ve affet Yelizaveta Bam.

İvan İvanoviç.

İki kahramanın dövüşü sona erdi.

(Pyotr Nikolayeviç dışarı taşınır.)

\section{Yelizaveta Bam.}

(Girerek.) Ah babacı̆̆ım, buradasın.

Çok sevindim,

Demin kooperatifteydim,

Şekerleme aldım yenice,

Çayın yanında pasta da olsun istedim.

Baba. 


\section{(Yakasını açarak.)}

Uf, amma yoruldum.

\section{Yelizaveta Bam.}

Ne yaptın ki?

Baba.

Şey... Odun kestim ve müthiş yorgunum.

\section{Yelizaveta Bam.}

İvan İvanoviç, bira dükkanına gidin ve bize bir şişe birayla nohut kapıp gelin.

\section{İvan İvanoviç.}

Aha, nohut ve yarım şişe bira, birahaneye gidilecek, oradan da buraya.

\section{Yelizaveta Bam.}

Yarım şişe değil, bir şişe bira; ayrıca birahaneye değil, nohuda gidilecek!

\section{İvan İvanoviç.}

Şimdi, kürkümü bira dükkanına saklayacağım, kafamın üstüneyse yarım bir nohut takacağım.

\section{Yelizaveta Bam.}

Ah hayır, gerek yok, sadece acele et, babacığım odun kesmekten yorgun düştü de.

\section{Baba.}

Ah şu kadınlar, anlayışları kıt, dopdolu zihinleri boşlukla.

\section{Anne.}

\section{(Girerek.)}

Yoldaşlar. Bu alçak kadın Mavo oğulun canına kıymış. ${ }^{29}$

29 Metinde bu cümle "Mavo sıyna eta merjavka ukokosıyla" (Маво сына эта мержавка укокосыла) şeklinde geçer. Bir anlam ifade etmeyen "merjavka" (мержавка) kelimesi, "alçak (kadın)" anlamına gelen "merzavka" (мерзавка) kelimesiyle, yine bir anlam ifade etmeyen "ukokosıyt" (укокосыть) fiilinin dişil çekimi olan "ukokosıyla" (укокосыла) kelimesi ise “öldürmek, canına kıymak” anlamlarına gelen "ukokoşit” (укокошить) fiiliyle değiştirilmiştir. 
(Dekorun arkasından iki kafa uzanır.)

\section{Kafalar.}

Hangisi? Hangisi?

Anne.

Şu işte, dudakları şöyle olan!

\section{Yelizaveta Bam.}

Anne anne, neler söylüyorsun?

\section{Anne.}

Sırf senin yüzünden berabere bitti oğlanın hayatı.

\section{Yelizaveta Bam.}

Bana kimden bahsettiğini söyler misin?

\section{Anne.}

(Kaya gibi bir suratla.)

Onlardaan! Onlardaan! Onlardaan!

\section{Yelizaveta Bam.}

Delirmiş!

\section{Anne.}

Mürekkep balığıyım ben!

(Dekorlar Anne ile Baba'yl yutar.)

\section{Yelizaveta Bam.}

Şimdi gelecekler, ne halt ettim ben!

\section{Anne.}

$3 \times 27=81$.

\section{Yelizaveta Bam.}


Beni yakalamak ve yeryüzünün suretinden silmek için mutlaka gelecekler. Kaçmak. Kaçmak lazım. Ama nereye kaçmalı? Bu kapı merdivenlere çıkıyor, kapıda onlarla karşılaşırım. Pencereden mi? (Pencereden bakar.) Ohoooo! Atlayamam. Çok yüksek! Peki ne yapmalıyım? Ah! Ayak sesleri geliyor. Bunlar onlar. Kapıyı kapatacağım ve açmayacağım. İstedikleri kadar çalsınlar. (Kapıyı kapatır.)

\section{Kapı Çalınır, Ardından Bir Ses.}

Yelizaveta Bam, size kanun namına kapıyı açmanızı emrediyorum.

$$
\text { (Sessizlik.) }
$$

\section{Birinci Ses.}

Size kapıyı açmanızı emrediyorum!

(Sessizlik.)

İkinci Ses.

(Sessizce.)

Haydi kapıyı kıralım.

\section{Birinci Ses.}

Yelizaveta Bam, açın; yoksa zorla gireceğiz!

\section{Yelizaveta Bam.}

Bana ne yapmak istiyorsunuz?

\section{Birinci.}

Cezaya çarptırıldınız.

\section{Yelizaveta Bam.}

Ne sebeple? Neden bana ne yaptığımı söylemek istemiyorsunuz?

\section{Birinci.}

Pyotr Nikolayeviç Krupernak’1 öldürmekle suçlanıyorsunuz.

\section{İkinci.}

Bu yüzden cevap verin. 


\section{Yelizaveta Bam.}

Ama ben kimseyi öldürmedim!

\section{Birinci.}

Ona mahkeme karar verir.

(Yelizaveta Bam kapıyı açar. İtfaiyeci kılığına girmiş Pyotr Nikolayeviç ve İvan İvanoviç içeri girerler.)

\section{Yelizaveta Bam.}

Size teslim oluyorum.

\section{Pyotr Nikolayeviç.}

Kanun namına tutuklusunuz.

\section{İvan İvanoviç.}

(Bir kibrit yakarak.)

Bizi takip edin.

\section{Yelizaveta Bam.}

(Bă̆ırır.)

Bağlayın beni! Örgülerimden sürükleyin! Yalağın ${ }^{30}$ içinden geçirin! Ben kimseyi öldürmedim. Ben kimseyi öldüremem!

\section{Pyotr Nikolayeviç.}

Yelizaveta Bam, sakin olun.

İvan İvanoviç.

Önünüze bakın.

\section{Yelizaveta Bam.}

Dağdaki kulübede artık küçük bir ateş yanıyor. Fareler bıyıklarını oynatıyor,

30 Burada "yalak" olarak çevirdiğimiz "корыто" (korıyto) kelimesinin diğer bir anlamı, geçmişte özellikle çamaşır yıkanırken kullanılan geniş tomruktan ya da metalden yapılan bir gereç olan "tekne”dir. Oyunun yazıldığı dönem düşünülünce kelimenin her iki anlamının da kullanılabileceği görülür. 
oynatıyorlar. Fırının üstündeyse kızıl yakalı gömleği ${ }^{31}$ ve elindeki baltayla Hamamböceği Hamamböceğioviç ${ }^{32}$ oturuyor.

\section{Pyotr Nikolayeviç.}

Yelizaveta Bam! Ellerinizi uzatıp keskin gözlerinizi kapatarak eklemlerinizin dengesine ve sinir şöleninize hâkim olarak adımlarımı takip edin. Arkamdan gelin.

(Yavaşça çıkarlar.)

Perde.

1927 yılı aralık ayının 12 'siyle 24 'ü arasında yazılmıştır.

\section{Kaynakça}

Kulica, erişim 16 Nisan 2018, https://dic.academic.ru/dic.nsf/ushakov/846030.

Harms, Daniil. Rasskazıy i povesti. Yelizaveta Bam, erişim 14 Nisan 2018, http://lib.ru/HARMS/harms.txt.

Harms, Daniil. Tsirk Şardam. Der. Valeriy Nikolayeviç Sajin. Sankt-Peterburg: Kristall, 2001.

31 Burada gömlek olarak çevirdiğimiz kıyafet, aslında rubaha'dır (pyбaxa). Rusların milli giysilerinin parçalarından biri olan bu kıyafet de gömlek gibi vücudun üst kısmına giyilir ve farklı renk ve desenlere sahip olabilir.

32 Rusçada isme gelen "oviç" kelimesi, baba adına işaret eder. Dolayısıyla "Hamamböceği Hamamböceğioviç" ifadesi, "Hamamböceği oğlu Hamamböceği” șeklinde de kullanılabilir. 
